\title{
Adequacy analysis of electric power systems with wind and solar power stations
}

\author{
Dmitriy Karamov ${ }^{1}$, Sergey Perzhabinsky ${ }^{1 *}$ \\ ${ }^{1}$ Melentiev Energy Systems Institute of SB RAS, Irkutsk, Russia
}

\begin{abstract}
We developed a new method of adequacy analysis of electric power systems with wind and solar power stations. There are storage batteries in the electric power system. Various types of storage batteries can be used in electric power systems. They are electrochemical, hydroelectric, heat or air storages. The modelling of wind speed and solar radiation is based on software «Local analysis of environmental parameters and solar radiation». The original combination of modern models of meteorological data processing is used in the software. For adequacy analysis of electric power system, we use nonsingle estimation of electricity sacrifice in random hour. Simulation of random values is carried out by the Monte Carlo method.
\end{abstract}

\section{Introduction}

Researches of adequacy of electric power systems are presented, for example, [1-5]. The method of adequacy analysis based on estimation of random states of electric power system was suggested in [4]. Simulation of random states in the method is carried out by the Monte Carlo method.

Modern electric power systems contain generators on renewable energy sources. Generation on wind and solar stations has random and oscillated character. Using of storage batteries in the such electric power system allows to stabilize of electricity supply. Appling of traditional method [4] for adequacy analysis of the electric power system is not possible Modification of the method under modern conditions supposes high quality of meteorological data processing, modelling of charging and discharging processes, simulating of random values of solar radiation and wind speed.

Scientific researches of adequacy analysis of electric power systems with wind power generators and different storage batteries are presented in articles [919]. However, we concentrate our attention on a research of R. Billinton [13-15] and Y-F. Li [9-11, 16]. Integration of wind power stations and storage batteries in the system along with detailed describing of adequacy analysis is considered in these articles. We also give high estimation of research of Ungjin Oh [12]. Ungjin Oh fully described of charge and discharge processes of storage batteries under solving of the problem of adequacy analysis of electric power system with wind power plants and energy storages.

In spite of high level of presented articles, it is necessary to research of impact of a quality of meteorological data on a system reliability level. In particular, we need to analyze of possibility of an employing of a real meteorological data of FM 12
Synop и METAR to estimate of adequacy of electric power system with power generators on renewable sources and energy storages. In world practice they recommend to use Rayleigh and Weibull distributions for wind speed simulations [20-23].

The aim of our article consists in the development of a new method for adequacy analysis of electric power systems with renewable sources and storage batteries. Various types of storage batteries can be used in electric power systems. They are electrochemical, hydroelectric, heat or air storages. A storage hydroelectric power station is most used as energy storage in large electric power systems. We talk about important things in modelling of work of wind and solar power stations in the first part of our article. The second part of our article contains a description of a modification of the model of electricity shortage estimation. Quadratic losses of electricity under transmission are took into account in the model. Theoretical research of the model [24] speaks about the efficiency of applying of the model under adequacy analysis of electric power systems. We represented results of an experimental research of test scheme of electric power system with wind, solar power generators and storage batteries in the third part of the article. As an object of research we used a real longterm meteorological data from the Russkiy island.

\section{Analysis of a long-term meteorological data}

One of the most important problem in the modelling of renewable energy sources is a processing of long-term meteorological data. The quality of analyzing of longterm meteorological data impacts on estimation of electricity generation and main parameters of the regime of a wind or solar power station.

Corresponding author: sergperj@gmail.com 
We are going to simulate of wind speed and solar radiation on a base of the earlier developed method for a reproduction of the environment state in the considered location [25]. The given method was represented by software «Local analysis of environmental parameters and solar radiation». Longterm meteorological data of FM 12 Synop and METAR are used in the software.

\subsection{The modelling of work of a wind power station}

For the computing of generated power on a wind station we used the follow classical formula [22, 23]

$$
P_{w}=\frac{s_{w} c_{w} \rho v^{3}}{2} \text {. }
$$

where $s_{w}$ is square of swept surface, $\mathrm{m}^{2}, c_{w}$ is a power coefficient, p.u., $\rho$ is air density, $\mathrm{kg} / \mathrm{m}^{3}, v$ is a wind speed, $\mathrm{m} / \mathrm{s}$. The aria of swept surface is computed by formula $s_{w}=\pi r^{2}$ for a wind power generator with horizontal axis of rotation where $r$ is radius of wind wheel.

Air density with humidity is found by the follow rule

$$
\rho=\frac{\rho_{d} R_{v}+\rho_{v} R_{d}}{R_{d} R_{v} t} .
$$

here, $\rho_{d}$ is partial pressure of dry air, $\mathrm{Pa}, R_{d}$ is a gas constant for dry air $(287,058 \mathrm{~J} / \mathrm{kg} \cdot \mathrm{K}), t$ is a temperature of outside air, $\mathrm{K}, \rho_{v}$ is a pressure of vapour, $\mathrm{Pa}, R_{v}$ is a pour constant $(461,495 \mathrm{~J} / \mathrm{kg} \cdot \mathrm{K})$.

Revaluation of a wind speed to a height of wind wheel tower is realized by

$$
v_{2}=v_{1}\left(h_{2} / h_{1}\right)^{\beta}
$$

where $v_{1}$ is a measured wind speed on a height of $10 \mathrm{~m}\left(h_{1}\right), v_{2}$ is correct wind speed on a working height $h_{2}, \quad \beta$ is a roughness coefficient of an underlying surface.

We analyzed of a wind power plant with horizontal axis of rotation «Enercon E-82 E2» in our research. «Enercon E-82 E2» is often used in littoral and offshore regions of European Union. The height of such wind power plant is equal $80 \mathrm{~m}$ and radius of the wind wheel is $40 \mathrm{~m}$.

\subsection{The modelling of work of a solar power station}

Generated power (W) of a solar panel depends on solar radiation rate and square of working surface. We'll be able to compute generated power by the next formula

$$
P_{s}=s_{s} c_{s} I_{t} \text {. }
$$

where $s_{s}$ is square of surface of the solar panel, $\mathrm{m}^{2}$, $c_{s}$ is a power coefficient of the solar panel, p.u., $I_{t}$ is a total solar radiation, $\mathrm{W} / \mathrm{m}^{2}$.
Solar radiation incoming to Earth is inconstant and depends on many parameters. Geographic coordinates, time zone, amount of days of a considered period, the time of the sun's appearance and others are unvarying parameters. Composition of clouds, albedo of Earth's surface, atmospheric mass, thickness of ozone screen, spectral distribution of shine, existence of vapour and aerosol in clouds are variable parameters.

First of all, we find a time of rise, zenith and sunset for every day of a considered period on a selected territory. After that we compute of direct $\left(I_{b}\right)$, diffuse $\left(I_{d}\right)$ and total $\left(I_{t}\right)$ solar radiation. A detailed description of a procedure of solar radiation computing is presented in [25].

Total solar radiation $\left(\mathrm{W} / \mathrm{m}^{2}\right)$ is defined by the rule

$$
I_{t}=\left(I_{b}+I_{d}\right) C_{r} \text {. }
$$

Here $C_{r}$ is a coefficient of decreasing of total solar radiation, $C_{r}=1-0,75(N / 8)^{3,4}$.

A value of cloudiness $N$ depends on grade of clouds covering a sky in some moment of time [25].

\subsection{The model of electricity shortage estimation}

We consider a scheme of electric power system with $n$ nodes and some set of system links. Let $N$ is a given number of modeled hours of electric power system work. An every hour of electric power system work is characterized by a set of random values such as generated electricity $\bar{x}_{i}^{k}$ in a node $i$, electricity demand $\bar{y}_{i}^{k}$ in a node $i$ and line capacity $\bar{z}_{i j}^{k}$ between nodes $i$ and $j, i=1, \ldots, n, j=1, \ldots, n, i \neq j, k=1, \ldots, N$.

It is set minimum $\overline{\Delta x}_{i}^{\text {min }}$ and maximum $\overline{\Delta x}_{i}^{\max }$ capacity of a storage battery which located in node $i$. For $k$-th hour electricity reserve $\underline{\Delta x}_{i}^{k}$ and residual capacity $\overline{\Delta x}_{i}^{k}$ of a storage battery are computed on a base of previous computations, $i=1, \ldots, n$, $k=1, \ldots, N$.

Let $x_{i}$ is electricity generated in a node $i, \Delta x_{i}$ is change of accumulated electricity in storage battery in a node $i, y_{i}$ is electricity consumption in a node $i, z_{i j}$ is electricity transmitted from node $i$ to node $j$, $i=1, \ldots, n, j=1, \ldots, n, i \neq j$.

The problem of electricity shortage estimation in $k$ th hour, $k=1, \ldots, N$, is written as:

$$
\begin{gathered}
G \sum_{i=1}^{n} y_{i}+\sum_{i=1}^{n} \Delta x_{i} \rightarrow \max , \\
x_{i}-y_{i}+\sum_{j=1}^{n}\left(1-a_{j i} z_{j i}\right) z_{j i}-\sum_{j=1}^{n} z_{i j}-\Delta x_{i}=0, \\
i=1, \ldots, n, i \neq j, \\
0 \leq y_{i} \leq \bar{y}_{i}^{k}, i=1, \ldots, n \\
0 \leq x_{i} \leq \bar{x}_{i}^{k}, i=1, \ldots, n
\end{gathered}
$$




$$
\begin{gathered}
-\underline{\Delta x}_{i}^{k} \leq \Delta x_{i} \leq \overline{\Delta x}_{i}^{k}, i=1, \ldots, n, \\
0 \leq z_{i j} \leq \bar{z}_{i j}^{k}, i=1, \ldots, n, j=1, \ldots, n, i \neq j .
\end{gathered}
$$

Here $a_{i j}$ is a nonnegative coefficient of electricity losses under transmission from node $i$ to node $j$, $i \neq j, \quad G$ is a high positive number. The weight coefficient $G$ is necessary for mainstreaming of minimization of electricity shortage. Variables $\Delta x_{i}$ can be negative. It means that electricity consumption is bigger than electricity generated in a current hour.

That's way electricity shortage is covered by means of consuming electricity from a storage battery. Let $\Delta x_{i}^{k-1}$ is an optimal value of a variable $\Delta x_{i}$ in the problem $(1)-(6)$ for $(k-1)-$ th hour. Values $\underline{\Delta x}_{i}^{k}$ and $\overline{\Delta x}_{i}^{k}, \quad i=1, \ldots, n, \quad k=2, \ldots, N, \quad$ are computed

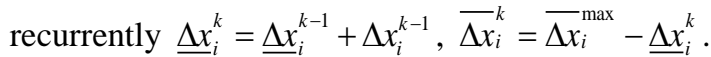
We suppose that a random value $\zeta_{i}$ is equally distributed on interval $\left[\overline{\Delta x}_{i}^{\min }, \overline{\Delta x}_{i}^{\max }\right], i=1, \ldots, n$. Any meaning of $\zeta$ can be used as $\underline{\Delta x}_{i}^{0}, i=1, \ldots, n$.

The described process of charging and consuming of electricity from storage battery is Markov process [15]. We can consider an optimal solution of the problem (6) - (12) as equally probable for every hour. The problem (6) - (12) has a solution because its feasible set is not empty (the point $y_{i}=0, x_{i}=0$, $\Delta x_{i}=0, \quad z_{i j}=0, i=1, \ldots, n, j=1, \ldots, n, i \neq j$, is feasible) and bounded according to (8) - (12), objective function is linear. Uniqueness of optimal values of $y_{i}$, $i=1, \ldots, n$, is followed from theorems [10].

Simulation of random values is realized on their distributions. Reliability indices and procedures of their computing are also discussed in [8].

\section{Experimental research}

Experimental research of developed method was played out on a test example [8]. The scheme of electric power system consists of 5 nodes и 5 system links (a fig.1).

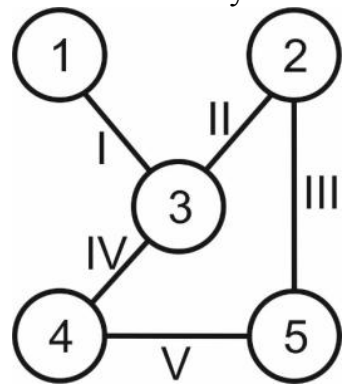

Fig.1. Scheme of electric power system

You'll be able to study of technical characteristics of the electric power system in a table 1 . Nodes in the system are linked by electric transmission lines with voltage of $220 \mathrm{kV}$ and a line capacity of $135 \mathrm{MW}$ with an integral coefficient of an accident 0,011 p.u. by 100 $\mathrm{km}$ and a coefficient of electricity losses 0,0001661 p.u. Wind, solar power stations and storage batteries are located in the node №1 of the electric power system.

Table 1. Technical characteristics of the electric power system

\begin{tabular}{|c|c|c|c|c|c|}
\hline $\begin{array}{c}\text { A } \\
\text { node } \\
\text { № }\end{array}$ & $\begin{array}{c}\text { Total } \\
\text { powe } \\
\text { r in a } \\
\text { node, } \\
\text { MW }\end{array}$ & $\begin{array}{c}\text { Max; } \\
\text { of } \\
\text { load, } \\
\text { MW }\end{array}$ & $\begin{array}{c}\text { A } \\
\text { link } \\
\text { No }\end{array}$ & $\begin{array}{c}\text { Quantity } \\
\text { of power } \\
\text { lines in a } \\
\text { link }\end{array}$ & $\begin{array}{c}\text { Leng } \\
\text { th, } \\
\text { km }\end{array}$ \\
\hline 1 & 600 & 700 & I & 2 & 200 \\
\hline 2 & 1000 & 700 & II & 2 & 100 \\
\hline 3 & 1400 & 1300 & I \& II & 1 & 300 \\
\hline 4 & 1000 & 1000 & IV & 2 & 200 \\
\hline 5 & 1200 & 1100 & V & 2 & 300 \\
\hline Total & 5200 & 4900 & - & - & - \\
\hline
\end{tabular}

We have analyzed of meteorological data from the Russkiy island for modelling of wind speed and solar radiation. There are 1892160 observations.

Processing of long-term meteorological data showed that a wind direction is northerly for autumn and winter seasons in the research location. While a wind direction is southerly for spring and summer terms. We used of pressure of air, temperature, humidity for computation of air density. Air density has high meanings for autumn and winter seasons from behind of low temperatures, high atmosphere pressure and low humidity. Opposite meanings of air density are observed for spring and summer seasons. Monthly average wind speed of more $5 \mathrm{~m} / \mathrm{s}$ on a height $10 \mathrm{~m}$. is observed for autumn and winter seasons.

We presented of monthly average wind speed on a height $80 \mathrm{~m}$. on a fig. 2 . You'll be able to see from a fig.2 that wind power plant would be worked in nominal regime from September through April

Results of adequacy analysis of the electric power system with wind power station of $20 \mathrm{MW}$ were obtained in [8]. Air density and storage batteries were not used in computation process of generated electricity. The probability of work without electricity shortage has meaning 0,994920 p.u. in this case. The mathematical expectation of electricity shortage is 0,196116 MWh.

We presented of results of computations of reliability indexes for the system with wind power plants and storage batteries in a table 2. A wind speed and volume of generated electricity were computed by described above formulas. 


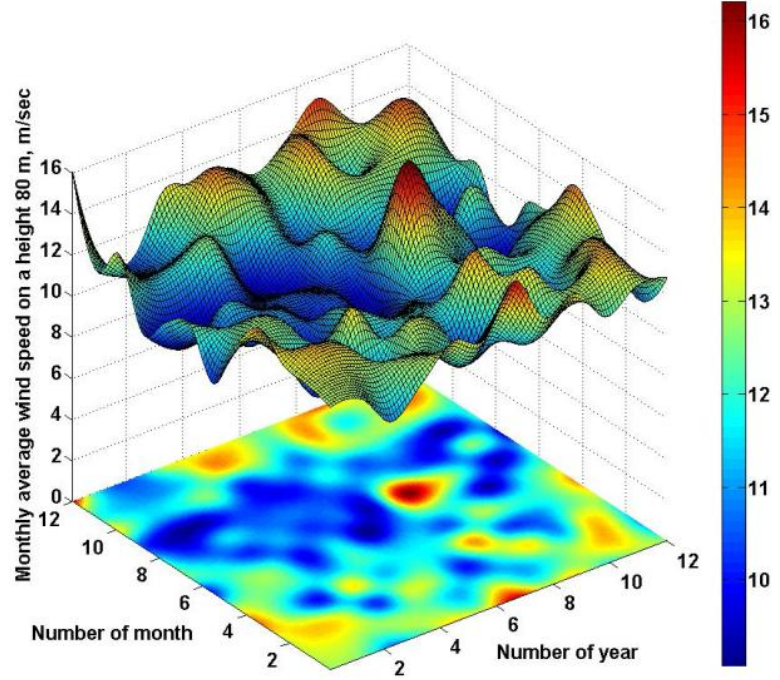

Fig. 2. Monthly average wind speed on a height $80 \mathrm{~m}$., the Russkiy island.

Table 2. Reliability indexes of the electric power system with wind power plants and storage batteries

\begin{tabular}{|c|c|c|c|}
\hline \multicolumn{2}{|c|}{$\begin{array}{c}\text { Structure of electric } \\
\text { power system }\end{array}$} & \multirow{2}{*}{$\begin{array}{l}\text { The } \\
\text { probability of } \\
\text { work without } \\
\text { electricity } \\
\text { shortage, p.u. }\end{array}$} & \multirow{2}{*}{$\begin{array}{c}\text { The } \\
\text { mathem; } \\
\text { expectation } \\
\text { of elec-ty } \\
\text { shortage, } \\
\text { MWh }\end{array}$} \\
\hline $\begin{array}{c}\text { Wind } \\
\text { power } \\
\text { plants, } \\
\text { MW }\end{array}$ & $\begin{array}{c}\text { Storage } \\
\text { batteries, } \\
\text { MWh }\end{array}$ & & \\
\hline \multirow{4}{*}{20} & - & 0,995890 & 0,135934 \\
\hline & 2 & 0,996120 & 0,147552 \\
\hline & 4 & 0,996220 & 0,169415 \\
\hline & 6 & 0,996630 & 0,123294 \\
\hline
\end{tabular}

Complete accounting of environmental data allowed to obtain more valid reliability indexes. Integration of storage batteries also increased reliability level of the electric power system. Herewith we can place $20 \mathrm{MW}$ of wind power plants and $2 \mathrm{MWh}$ of storage batteries in the electric power system for obtaining of requested reliability level $(0,996$ for probability of work without electricity shortage). We presented of changing of solar radiation of the Russkiy island for twelve's year observations on a fig.3. You can see that solar radiation is most intensive from April through November. Results of adequacy estimation of electric power system with solar power plants and storage batteries are presented in a table 3 .

Table 3. Reliability indexes of the electric power system with solar power plants and storage batteries

\begin{tabular}{|c|c|c|c|}
\hline \multicolumn{2}{|c|}{$\begin{array}{c}\text { Structure of electric } \\
\text { power system }\end{array}$} & \multirow{2}{*}{$\begin{array}{c}\text { The } \\
\text { probability of } \\
\text { work without } \\
\text { electricity } \\
\text { shortage, p.u. }\end{array}$} & \multirow{2}{*}{$\begin{array}{c}\text { The } \\
\text { mathem; } \\
\text { expectation } \\
\text { of elec-ty } \\
\text { shortage, } \\
\text { MWh }\end{array}$} \\
\hline $\begin{array}{c}\text { Solar } \\
\text { power } \\
\text { plants, } \\
\text { MW }\end{array}$ & $\begin{array}{c}\text { Storage } \\
\text { batteries, } \\
\text { MWh }\end{array}$ & & \\
\hline \multirow{4}{*}{10} & 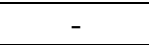 & 0,995002 & 0,169478 \\
\hline & 2 & 0,995501 & 0,131489 \\
\hline & 10 & 0,996321 & 0,106480 \\
\hline & 15 & 0,997403 & 0,095589 \\
\hline
\end{tabular}

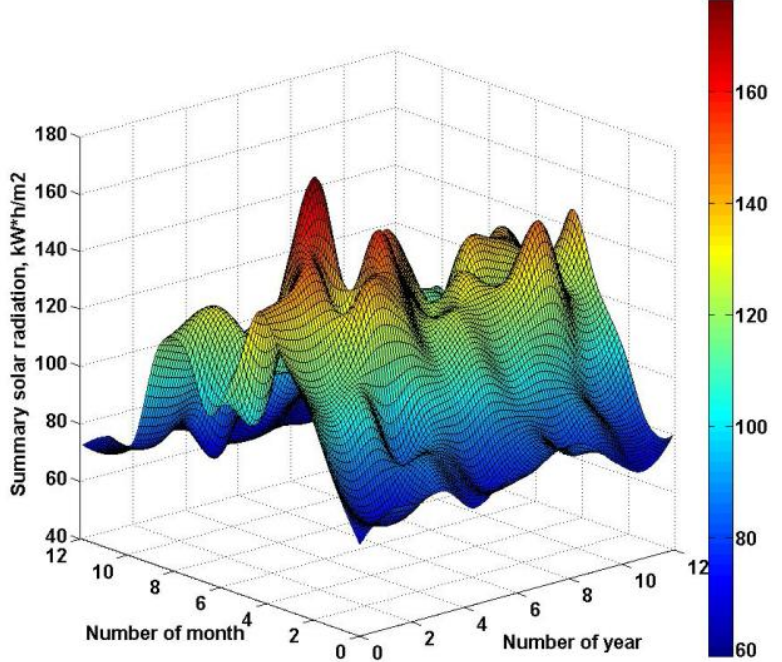

Fig. 3. Changing of solar radiation of the Russkiy island for twelve's year observations

Results of experimental research confirm a fact that for using of solar power plants in electric power system we need bigger storage batteries.

\section{Conclusion}

The new model of adequacy analysis of electric power system with wind and solar power plants and storage batteries is presented in the article. We use the software «Local analysis of environmental parameters and solar radiation» for detailed modelling of environmental conditions on the considered territory. Complete accounting of environmental data increases of efficiency of modelling of power plants based on renewable sources. Results of our experimental research confirm of correctness of the above statement. Accounting of air density under modelling of wind power plants increases validity of reliability indexes. Integration of storage batteries into electric power systems with wind and solar power plants also increases reliability level and stabilizes of regime indexes. Herewith storage batteries are momentary power reserve. Increase of capacity of storage batteries leads to decrease the mathematical expectation of electricity shortage. Modelling of charging and discharging processes in a storage battery is presented in a view as Markov process. This fact allows to increase computational efficiency of the method.

\section{References}

1. G.F. Kovalev, L.M. Lebedeva, Reliability of power systems (Novosibirsk, Nauka, 2015, 224 p.)

2. R. Billinton, R.N. Allan, Reliability Evaluation of Power Systems, Plenum Publishing (New York, 1996)

3. Yu. YA. Chukreev, Model of reliability of electric power systems (Syktyvkar, Nauka, 1995, 176 p.)

4. Y.N. Rudenko, M.B. Chelcov Reliability and redundancy in power systems (Novosibirsk, Nauka, 1974, 263 p.) 
5. G.F. Kovalev, L.M. Lebedeva, Complex models of optimizing the design state regimes in assessing the reliability of electric power systems (Irkutsk, ESI SB RAS, 2000, 73 p.)

6. D.S. Krupenev, S.M. Perzhabinskiy, Algorithm for optimizing the balance reliability of electric power systems, J. Proceedings of the Russian Academy of Sciences. Power Engineering, 2, (2014)

7. D.S. Krupenev, S.M. Perzhabinskiy, Applying average dual estimations in algorithm for optimal reliability of electic power system, J. Managing large systems, 54, (2015)

8. D.S. Krupenev, S.M. Perzhabinskiy, Assessment of the reliability of electric power systems with wind power plants, J. Proceedings of the Russian Academy of Sciences. Power Engineering, 2, (2017)

9. Y. Li., E. Zio. Uncertainty analysis of the adequacy assessment model of a distributed generation system // Renewable Energy. - 2012. - V. 41. - P. 235-244.

10. R. Rocchetta., Y.F. Li., E. Zio. Risk assessment and risk-cost optimization of distributed power generation systems considering extreme weather conditions // Reliability Engineering \& System Safety. - 2015. - V. 136. - P. 47-61.

11. Y. Li., E. Zio. A multi-state model for the reliability assessment of a distributed generation system via universal generating function // Reliability Engineering \& System Safety. - 2012. - V. 106. - P. 28-36.

12. U. Oh, J. Choi, H-h. Kim. Development of Reliability Contribution Function of Power System including Wind Turbine Generators combined with Battery Energy Storage System // The Transactions of The Korean In-stitute of Electrical Engineers. - 2016. V. 65. - P. 371-381.

13. W. Wangdee, R. Billinton. Reliability assessment of bulk electric systems containing large wind farms // International Journal of Electrical Power \& Energy Systems. - 2007. - V. 29. - P. 759-766.

14. K. Xie., R. Bilinton. Energy and reliability benefits of wind energy conversion systems // Renewable Energy. - 2011. - V. 366. - P. 1983-1988.

15. R Billinton, H. Chen, R. Ghajar. Time-series models for reliability evaluation of power systems including wind energy // Reliability evaluation of power systems. - 1996. - V. 36. - P. 1253-1261.

16. R. Ak, Y-F. Li, V. Vitelli, E. Zio. Adequacy assessment of a wind-integrated system using neural network-based interval predictions of wind power generation and load // International Journal of Electrical Power \& Energy Systems. - 2018. - V. 98. - P. 213226.

17. N. Shi, Y, Luo. Energy Storage System Sizing Based on a Reliability Assessment of Power Systems Integrated with Wind Power // Sustainability. - 2017. V. 9. - P. 395-415.

18. M. N. Scheu, D. Matha, M. Muskulus. Validation of a Markov-based Weather Model for Simulation of O\&M for Offshore Wind Farms // The Twenty-second
International Offshore and Polar Engineering Conference. - 2012. - P. 1-6.

19. M. N. Scheu, A. Kolios, T. Fischer, F. Brennan. Influence of statistical uncertainty of component reliability estimations on offshore wind farm availability // Reliability Engineering \& System Safety. - 2017. - V. 168. - P. 28-39.

20. A. Ilinca, E. McCarthy, J.-L. Chaumel, J.-L. Retiveau. Wind potential assessment of Quebec Province // Renewable Energy. - 2003. - V. 28. - P. 1881-1897.

21. W. Jojola-Talburt, J. Reimann, A. John. Native American Wind Resource Atlas. Office of Indian Energy and Economic Development. Division of Energy and Mineral Development. 2010 Edition. URL: https://www.bia.gov/sites/bia.gov/files/assets/asia/ieed/ieed/pdf/idc013229.pdf

22. Nikolaev V.G, Ganaga S.V, Kudryashov Yu.I, National cadaster of Russia wind energy resources and methodology for their determination (Moscow, Atmograph, 2008. 584 p)

23. Nikolaev V.G. Resource and feasibility study of large-scale development of wind power in Russia (Moscow, Atmograph, 2011.501 p)

24. V.I. Zorkaltsev, S.M. Perzhabinskiy, Model of shortage optimization in electric power system, J. Managing large systems, 30.1, (2010)

25. Karamov D.N. Mathematical modelling of an autonomous power supply system using renewable energy sources. Bulletin of Irkutsk State Technical University, 2015, vol. 104, no. 9, pp. 133-140. In Rus.

26. Karamov D.N. Mathematical modeling of solar radiation based on open access long-term meteorological observation data. Bulletin of the Tomsk Polytechnic University. Geo Assets Engineering, 2017, vol. 328, no. 6. 28-37. In Rus.

27. S.M. Perzhabinsky., D.N. Karamov. Method for analysing the adequacy of electric power systems with wind power plants and energy storages. E3S Web of Conferences, 2017, vol. 25, no. 1. 1-5.

28. Wong L.T., Chow W.K. Solar radiation model // Applied Energy. - 2001. - V. 69. - P. 191-224.

29. Kasten F., Czeplak G. Solar and terrestrial radiation dependent on the amount and type of cloud // Solar Energy. - 1980. - V. 24. - P. 177-189. 